\title{
Serum Alkaline Phosphatase in Cryptogenic Stroke Cases with Active Cancer
}

\author{
Tesseki Izumi, Hitoki Nanaura, Naohiko Iguchi, Maki Ozaki and Kazuma Sugie
}

\begin{abstract}
:
Objective We assessed the relationship between the levels of serum alkaline phosphatase, which is often increased with biliary obstruction and bone metastasis, and active cancer in patients with cryptogenic stroke.

Methods Serum alkaline phosphatase levels in patients with cryptogenic stroke sampled upon admission were measured using the Japan Society of Clinical Chemistry method used in Japan. Active cancer was defined as a new diagnosis, treatment, progression, or recurrence within six months before admission or metastatic cancer. Multivariate logistic regression analyses were performed to explore the relationship between serum alkaline phosphatase and active cancer in these patients.

Results Among the 249 patients classified as having cryptogenic stroke, 64 had active cancer. Patients with cryptogenic stroke with active cancer had significantly higher serum alkaline phosphatase levels $(486 \pm 497$ vs. $259 \pm 88.2 \mathrm{U} / \mathrm{L} ; \mathrm{p}<0.001)$ than those without cancer. Multivariate logistic analysis revealed that serum alkaline phosphatase levels $\geq 286 \mathrm{U} / \mathrm{L}$ were associated with cryptogenic stroke with active cancer [odds ratio (OR), 2.669, 95\% confidence interval $(\mathrm{CI}), 1.291-5.517 ; \mathrm{p}=0.008$ ] independent of age $\leq 70$ years old (OR, 3.303, 95\% CI, 1.569-6.994; $\mathrm{p}=0.002$ ), male sex (OR, 0.806, 95\% CI, 0.380-1.710; $\mathrm{p}=0.573$ ), and serum D-dimer levels $\geq 2.6 \mu \mathrm{g} / \mathrm{mL}$ (OR, 18.78, 95\% CI, 8.130-43.40; $<<0.001$ ).

Conclusion In patients with cryptogenic stroke, high serum alkaline phosphatase levels may be related to active cancer.
\end{abstract}

Key words: alkaline phosphatase, cryptogenic stroke, cancer, stroke

(Intern Med 61: 639-646, 2022)

(DOI: 10.2169/internalmedicine.7550-21)

\section{Introduction}

Various studies investigating the biomarkers of ischemic stroke have demonstrated that elevated values of Ddimer (1, 2, 3), C-reactive protein $(1,4,5)$, hematocrit (5), neutrophil (6), lactate dehydrogenase (7), platelet (8), low density lipoprotein (9), and eicosapentaenoic acid (10) were related to ischemic stroke associated with active cancer, suggesting the involvement of nonbacterial thrombotic endocarditis (11), drugs (12), radiations (13), dehydration (11), tumor embolism (11), infection (14), malnutrition (3, 10), a hypercoagulable state (15), and an inflammatory state (16).

In adenocarcinoma, which is associated with cryptogenic stroke with active cancer, metastasis has often been found in the liver and bone (17), which can lead to increasing serum alkaline phosphatase levels (18). We therefore suspected that serum alkaline phosphatase, one of the most widely used markers in routine blood tests, might be useful in the diagnosis of active cancer and metastasis in patients with cryptogenic stroke.

The present study assessed the characteristics of serum alkaline phosphatase levels in patients with cryptogenic stroke.

\section{Materials and Methods}

Consecutive patients who had acute symptomatic ischemic stroke and were admitted at or consulted with the Department of Neurology, Nara Medical University Hospital, Nara, Japan, within seven days of the onset between January 2005 and September 2020 were prospectively studied.

The age, gender, stroke risk factors (including hyperten- 
sion, diabetes mellitus, hyperlipidemia, current smoking, arterial fibrillation, and history of stroke), and the period from stroke onset to admission were recorded for all patients. All patients underwent magnetic resonance imaging (MAGNETOM Verio; Siemens Healthcare, Erlangen, Germany), 12lead electrocardiography, cardiac monitoring for at least $24 \mathrm{~h}$ with automated rhythm detection, and routine blood tests, including those for serum alkaline phosphatase. Serum alkaline phosphatase was measured upon admission using the Japan Society of Clinical Chemistry (JSCC) method used in Japan.

Patients with cryptogenic stroke were identified from a cohort of patients according to the Trial of Org 10172 in Acute Stroke Treatment classification, excluding conventional mechanisms (i.e. large-artery atherosclerosis, smallvessel occlusion, cardioembolism, and other determined etiologies), after which the presence or absence of active cancer was determined. Active cancer was defined as that diagnosed in any of the specialized departments within six months prior to enrollment, any treatment for cancer within the previous six months, or recurrent or metastatic cancer, as described previously (19). Patients with primary brain tumors $(n=1)$ and hematological malignancies $(n=2)$ were excluded. This study also examined the clinical characteristics of patients with and without active cancer, including serum alkaline phosphatase levels on admission. Given the small sample size of this study, those with liver, bile duct, gallbladder, and pancreatic head cancer were classified as having biliary obstructing cancer upon an analysis of the serum alkaline phosphatase levels. Metastasis was diagnosed based on the discretion of the department treating each active cancer and plain or enhanced chest-abdominal computed tomography findings by radiologist.

Hypertension was defined as a systolic blood pressure $>140 \mathrm{mmHg}$ or diastolic blood pressure $>90 \mathrm{mmHg}$ (or both) or the current use of antihypertensive medications. Hypercholesterolemia was defined as a total cholesterol level $>220 \mathrm{mg} / \mathrm{dL}$ or the current use of oral cholesterol-lowering agents. Diabetes mellitus was defined as a glycosylated hemoglobin concentration $>6.5 \%$ or the current use of oral hypoglycemic agents. Patients who smoked at least one cigarette per day were classified as smokers, whereas those who had never smoked or had stopped smoking for over five years were classified as nonsmokers.

\section{Statistical Analyses}

Statistical analyses were performed using the StatView version 5 statistical software program (Abacus Concepts, Berkeley, USA) and EZR (Saitama Medical Center, Jichi Medical University, Japan), which is based on $\mathrm{R}$ and $\mathrm{R}$ commander (20). All variables were expressed as means \pm standard deviation. The statistical significance of intergroup differences was assessed using Fisher's exact test for categorical variables and the Mann-Whitney $U$ test and KruskalWallis $U$ test for continuous variables. Multivariate logistic regression analyses were performed to explore relationships between serum alkaline phosphatase levels and cryptogenic stroke with active cancer using the age, sex, and serum Ddimer levels, which have been considered strong predictive factors for cryptogenic stroke associated with cancer. Cut-off values for continuous variables were determined using the area under the receiver operating characteristic (ROC) curve. $\mathrm{p}$ values $<0.05$ were considered statistically significant.

This study was approved by the Ethics Committee of Nara Medical University School of Medicine, who waived the need for informed consent given that our study design carried minimal risk.

\section{Results}

Among the 944 patients with consecutive acute ischemic stroke admitted within 7 days of onset enrolled in this study, a total of 249 (26\%) had cryptogenic stroke (160 men, 89 women; mean age, 70.6 \pm 12.6 years old). Among the 249 patients with cryptogenic stroke, 64 (26\%; 37 men, 27 women; mean age, $68.7 \pm 10.8$ years) had active cancer, including lung (17; 27\%); pancreatic (9; head in 8 and body in $1 ; 14 \%)$; stomach $(7 ; 11 \%)$, gallbladder $(5 ; 8 \%)$; liver $(4$; $6 \%)$; urinary bladder and uterine $(3 ; 5 \%)$; bile duct, rectal, kidney, ovarian, and breast $(2 ; 3 \%)$; and duodenal, appendix, adrenal, prostatic, peritoneal, and skin cancer $(1 ; 2 \%)$ (Fig. 1).

Regarding the cancer status, 31 patients had adenocarcinoma (48\%), 41 had stage IV cancer (64\%), 11 had stage III (17\%), 12 had stage I or II (19\%), 5 had cancer diagnosed after stroke (8\%), 30 were taking anticancer drugs (47\%), and 7 were undergoing radiation therapy (11\%) (Table 1). The patients with cryptogenic stroke and active cancer had significantly less hypertension [23 (36\%) vs. 108 $(58 \%)$; p $<0.01]$, history of stroke [2 (3\%) vs. $38(21 \%) ; \mathrm{p}<$ $0.001]$ and premedication with antiplatelet drugs [6 (9\%) vs. 56 (30\%); $<<0.001]$, significantly higher serum D-dimer levels $(16.1 \pm 19.7$ vs. $3.08 \pm 5.48 \mu \mathrm{g} / \mathrm{mL} ; \mathrm{p}<0.001)$, significantly more diffusion-weighted imaging patterns suggesting multiple infarct lesions involving $>1$ vascular territory [57 (89\%) vs. $64(35 \%) ; \mathrm{p}<0.001]$ including the internal carotid artery [61 (95\%) vs. $134(72 \%) ; \mathrm{p}<0.001]$ and vertebral basilar artery regions [41 (64\%) vs. $66(36 \%) ; \mathrm{p}<0.001]$, and a sig-

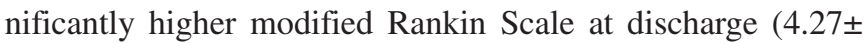
1.82 vs. $2.80 \pm 1.56$; $\mathrm{p}<0.001$ ), than those without active cancer (Table 1). Patients with cryptogenic stroke with active cancer also had significantly higher serum alkaline phosphatase levels than those without cancer $(486 \pm 497$ vs. $259 \pm$ 88.2 U/L; p<0.001).

The ability of serum alkaline phosphatase levels to identify the cryptogenic stroke with active cancer was assessed using ROC curve analysis. The best serum alkaline phosphatase cut-off value for predicting cryptogenic stroke with active cancer was $286 \mathrm{U} / \mathrm{L}$, with a sensitivity and specificity of $56.2 \%$ and $75.1 \%$, respectively. Cut-off levels for other variables that had high sensitivity and high specificity for identifying cryptogenic stroke with active cancer included 


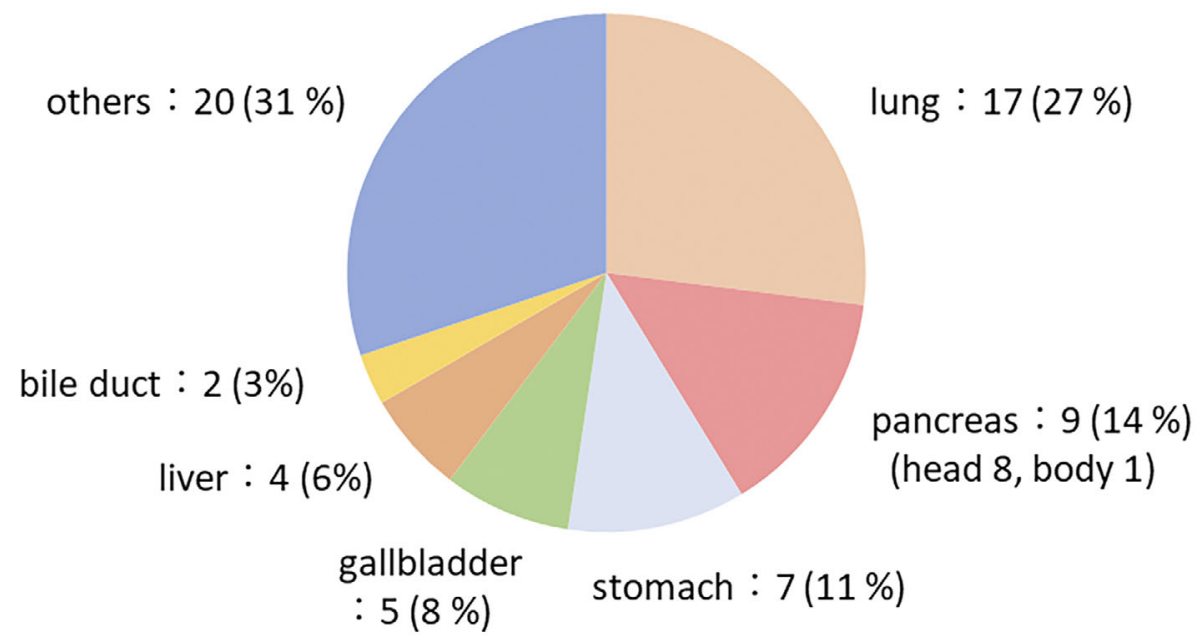

Figure 1. Cancer type in cryptogenic stroke with active cancer. Of the 64 patients with active cancer, $17(27 \%)$ had lung cancer, 9 (head 8, body 1; 14\%) had pancreatic cancer, 7 (11\%) had stomach cancer, $5(8 \%)$ had gallbladder cancer, $4(6 \%)$ had liver cancer, and $2(3 \%)$ had bile duct cancer.

age $\leq 70$ years (sensitivity, $56.2 \%$; specificity, $61.6 \%$ ) and serum D-dimer levels $\geq 2.6 \mu \mathrm{g} / \mathrm{mL}$ (sensitivity, $84.4 \%$; specificity, 75.7\%). A multivariate logistic analysis revealed that serum alkaline phosphatase levels $\geq 286 \mathrm{U} / 1$ were associated with cryptogenic stroke with active cancer [odds ratio (OR), 2.669, 95\% confidence interval (CI), 1.291-5.517; $\mathrm{p}=0.008$ ], independent of age $\leq 70$ years old (OR, 3.303, 95\% CI, 1.569-6.994; $\mathrm{p}=0.002)$, male sex (OR, 0.806, 95\% CI, $0.380-1.710 ; \mathrm{p}=0.573)$, and serum D-dimer levels $\geq 2.6 \mu \mathrm{g} /$ $\mathrm{mL}$ (OR, 18.78, 95\% CI, 8.130-43.40; p<0.001) (Table 2).

Patients with primary biliary obstructing cancer had sig-

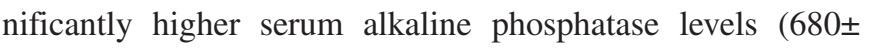
$632 \mathrm{U} / \mathrm{L}, \mathrm{n}=19)$ than those with other primary cancers, excluding biliary obstructing and lung cancers $(416 \pm 438 \mathrm{U} / \mathrm{L}$, $\mathrm{n}=28 ; \mathrm{p}=0.049)$ and primary lung cancer $(384 \pm 368 \mathrm{U} / \mathrm{L}, \mathrm{n}=$ $17 ; \mathrm{p}=0.005)$, and those without cancer $(259 \pm 88.2 \mathrm{U} / \mathrm{L}, \mathrm{n}=$ 185; $\mathrm{p}<0.0001)$. No significant difference in serum alkaline phosphatase levels was observed between the patients with primary lung cancer $(384 \pm 368 \mathrm{U} / \mathrm{L}, \mathrm{n}=17)$ and those without cancer (259 $\pm 88.2 \mathrm{U} / \mathrm{L}, \mathrm{n}=185, \mathrm{p}=0.526)$ (Table 3, Fig. 2).

Patients with liver and bone metastasis $(1,092 \pm 864 \mathrm{U} / \mathrm{L}, \mathrm{n}$ $=7)$, liver metastasis $(706 \pm 654 \mathrm{U} / \mathrm{L}, \mathrm{n}=14)$, and bone metastasis $(366 \pm 137 \mathrm{U} / \mathrm{L}, \mathrm{n}=4)$ had significantly higher serum alkaline phosphatase levels than those without cancer $(259 \pm$ 88.2 U/L, $\mathrm{n}=185 ; \mathrm{p}=0.004, \mathrm{p}<0.0001$, and $\mathrm{p}=0.034$; respectively) (Table 3, Fig. 3). The patients with stage IV cancer $(595 \pm 586 \mathrm{U} / \mathrm{L}, \mathrm{n}=41)$, adenocarcinoma $(492 \pm 518 \mathrm{U} / \mathrm{L}, \mathrm{n}=$ $31)$, cancer diagnosed after stroke $(462 \pm 336 \mathrm{U} / \mathrm{L}, \mathrm{n}=5)$, premedication of anticancer drugs $(559 \pm 555 \mathrm{U} / \mathrm{L}, \mathrm{n}=30)$, and premedication of antithrombotic drugs $(786 \pm 929 \mathrm{U} / \mathrm{L}, \mathrm{n}=10)$ also had significantly higher serum alkaline phosphatase levels than those without cancer $(259 \pm 88.2 \mathrm{U} / \mathrm{L}, \mathrm{n}=185 ; \mathrm{p}<$ $0.0001, \mathrm{p}=0.009, \mathrm{p}=0.048, \mathrm{p}<0.0001$, and $\mathrm{p}=0.020$; respectively) (Table 3).

\section{Discussion}

To our knowledge, our is the first study to demonstrate that high serum alkaline phosphatase levels are associated with active cancer in patients with cryptogenic stroke, even after adjusting for serum D-dimer levels, which are considered a strong predictive factor for cryptogenic stroke associated with cancer. Furthermore, high serum alkaline phosphatase levels in patients with cryptogenic stroke were associated with primary biliary obstructing cancer and liver or bone metastasis.

Multiple factors are involved in the pathogenic mechanism of cryptogenic stroke with active cancer, such as nonbacterial thrombotic endocarditis (11), drugs (12), radiation (13), dehydration (11), tumor embolism (11), infection (14), malnutrition (3,10), a hypercoagulable state (15), and an inflammatory state (16). Although the exact mechanism has not been determined in our patients with active cancer, the onset of cerebral infarction occurred significantly more often in the multivascular region than in other regions. In addition, the D-dimer levels and modified Rankin Scale at the time of discharge were significantly higher than in the patients suffering from cryptogenic stroke without active cancer, which is consistent with the previously reported characteristics of cryptogenic stroke with active cancer $(2,5,21)$. Therefore, we suspect that the cryptogenic stroke in our patients with active cancer was caused by multiple previously reported mechanisms. Furthermore, the rates of hypertension and a history of stroke, which were thought to be related to the risk factors of ischemic stroke, were significantly lower in our patients with active cancer than in those without active cancer, and the serum alkaline phosphatase levels were found to be significantly higher in our patients with active cancer than in those without active cancer.

Elevated serum alkaline phosphatase can occur in a wide 
Table 1. Clinical Characteristics of Patients with Cryptogenic Stroke with and without Active Cancer.

\begin{tabular}{|c|c|c|c|}
\hline & $\begin{array}{c}\text { with cancer } \\
(\mathrm{n}=64)\end{array}$ & $\begin{array}{l}\text { without cancer } \\
(\mathrm{n}=185)\end{array}$ & $\mathrm{p}$ value \\
\hline Age $(y)$ & $68.7 \pm 10.8$ & $71.3 \pm 13.1$ & 0.05 \\
\hline Male gender $(\%)$ & $37(58)$ & $123(66)$ & 0.22 \\
\hline Hypertension (\%) & $23(36)$ & $108(58)$ & $<0.01$ \\
\hline Diabetes mellitus (\%) & $16(25)$ & $52(28)$ & 0.75 \\
\hline Hyperlipidemia (\%) & $11(17)$ & $53(29)$ & 0.10 \\
\hline Smoking (\%) & $31(48)$ & $87(47)$ & 0.96 \\
\hline History of stroke (\%) & $2(3)$ & $38(21)$ & $<0.001$ \\
\hline Onset to hospital (h) & $27.5 \pm 35.6$ & $20.3 \pm 32.7$ & 0.05 \\
\hline Multiple vascular regions (\%) & $57(89)$ & $64(35)$ & $<0.001$ \\
\hline Internal carotid artery regions $(\%)$ & $61(95)$ & $134(72)$ & $<0.001$ \\
\hline Vertebral basilar artery regions $(\%)$ & $41(64)$ & $66(36)$ & $<0.001$ \\
\hline \multicolumn{4}{|l|}{ Premedication with antithrombotic drugs (\%) } \\
\hline Antiplatelet & $6(9)$ & $56(30)$ & $<0.001$ \\
\hline Anticoagulant & $4(6)$ & $12(6)$ & 1.00 \\
\hline modified Rankin Scale at discharge & $4.27 \pm 1.82$ & $2.80 \pm 1.56$ & $<0.001$ \\
\hline \multicolumn{4}{|l|}{ Cancer pathology (\%) } \\
\hline Adenocarcinoma & $31(48)$ & & \\
\hline Others & $14(22)$ & & \\
\hline Unknown & $19(30)$ & & \\
\hline \multicolumn{4}{|l|}{ Cancer stage (\%) } \\
\hline IV & $41(64)$ & & \\
\hline III & $11(17)$ & & \\
\hline II or I & $12(19)$ & & \\
\hline Cancer diagnosed after stroke $(\%)$ & $5(8)$ & & \\
\hline Premedication with anticancer drugs (\%) & $30(47)$ & & \\
\hline Radiation therapy (\%) & $7(11)$ & & \\
\hline \multicolumn{4}{|l|}{ Laboratory findings } \\
\hline D-dimer $(\mu \mathrm{g} / \mathrm{mL})$ & $16.1 \pm 19.7$ & $3.08 \pm 5.48$ & $<0.001$ \\
\hline Albumin $(\mathrm{g} / \mathrm{L})$ & $33.3 \pm 6.40$ & $39.1 \pm 6.10$ & $<0.001$ \\
\hline C-reactive protein $\left(10^{4} \mu \mathrm{g} / \mathrm{L}\right)$ & $4.35 \pm 4.75$ & $1.64 \pm 4.45$ & $<0.001$ \\
\hline White blood cell count (109/L) & $9.28 \pm 9.26$ & $7.64 \pm 3.35$ & 0.75 \\
\hline Hemoglobin (g/L) & $111 \pm 38.9$ & $132 \pm 23.4$ & $<0.001$ \\
\hline Hematocrit (1/L) & $0.33 \pm 0.07$ & $0.40 \pm 0.08$ & $<0.001$ \\
\hline Platelet $\left(10^{9} / \mathrm{L}\right)$ & $182 \pm 79.9$ & $223 \pm 75.0$ & $<0.001$ \\
\hline Alkaline phosphatase (U/L) & $486 \pm 497$ & $259 \pm 88.2$ & $<0.001$ \\
\hline
\end{tabular}

Values are reported as number (\%), mean \pm standard deviation, or median (interquartile ranges).

Table 2. Results of a Multivariate Logistic Analysis of Variables Independently Associated with the Presence of Cryptogenic Stroke with Active Cancer.

\begin{tabular}{cccc}
\hline & OR & $95 \%$ CI & p value \\
\hline Age $\leq 70$ years old & 3.303 & $1.560-6.994$ & 0.002 \\
Male sex & 0.806 & $0.380-1.710$ & 0.573 \\
D-dimer $\geq 2.6(\mu \mathrm{g} / \mathrm{mL})$ & 18.78 & $8.130-43.40$ & $<0.001$ \\
Alkaline phosphatase $\geq 286(\mathrm{U} / \mathrm{L})$ & 2.669 & $1.291-5.517$ & 0.008 \\
\hline
\end{tabular}

CI: confidence interval 
Table 3. Serum Alkaline Phosphatase Levels in Cryptogenic Stroke Cases with Active Cancer.

\begin{tabular}{|c|c|c|}
\hline & Alkaline phosphatase (U/L) & p value * \\
\hline \multicolumn{3}{|l|}{ Primary cancer } \\
\hline Biliary obstructing cancer $(n=19)$ & $680 \pm 632$ & $<0.0001$ \\
\hline Other cancers (except for biliary obstructing and lung cancer) $(n=28)$ & $416 \pm 438$ & 0.003 \\
\hline Lung cancer $(\mathrm{n}=17)$ & $384 \pm 368$ & 0.526 \\
\hline \multicolumn{3}{|l|}{ Metastatic cancer } \\
\hline Liver and bone metastasis $(\mathrm{n}=7)$ & $1,092 \pm 864$ & 0.004 \\
\hline Liver metastasis $(\mathrm{n}=14)$ & $706 \pm 654$ & $<0.0001$ \\
\hline Bone metastasis $(n=4)$ & $366 \pm 137$ & 0.034 \\
\hline Stage IV cancer $(n=41)$ & $595 \pm 586$ & $<0.0001$ \\
\hline Adenocarcinoma $(\mathrm{n}=31)$ & $492 \pm 518$ & 0.009 \\
\hline Cancer diagnosed after stroke $(n=5)$ & $462 \pm 336$ & 0.048 \\
\hline Premedication with anticancer drugs $(n=30)$ & $559 \pm 555$ & $<0.0001$ \\
\hline Premedication with antithrombotic drugs $(n=10)$ & $786 \pm 929$ & 0.020 \\
\hline
\end{tabular}

*; compared with serum alkaline phosphatase levels in cryptogenic stroke cases without cancer $(259 \pm 88.2, n=185)$.

Values are reported as number $(\%)$, mean \pm standard deviation, or median (interquartile ranges).

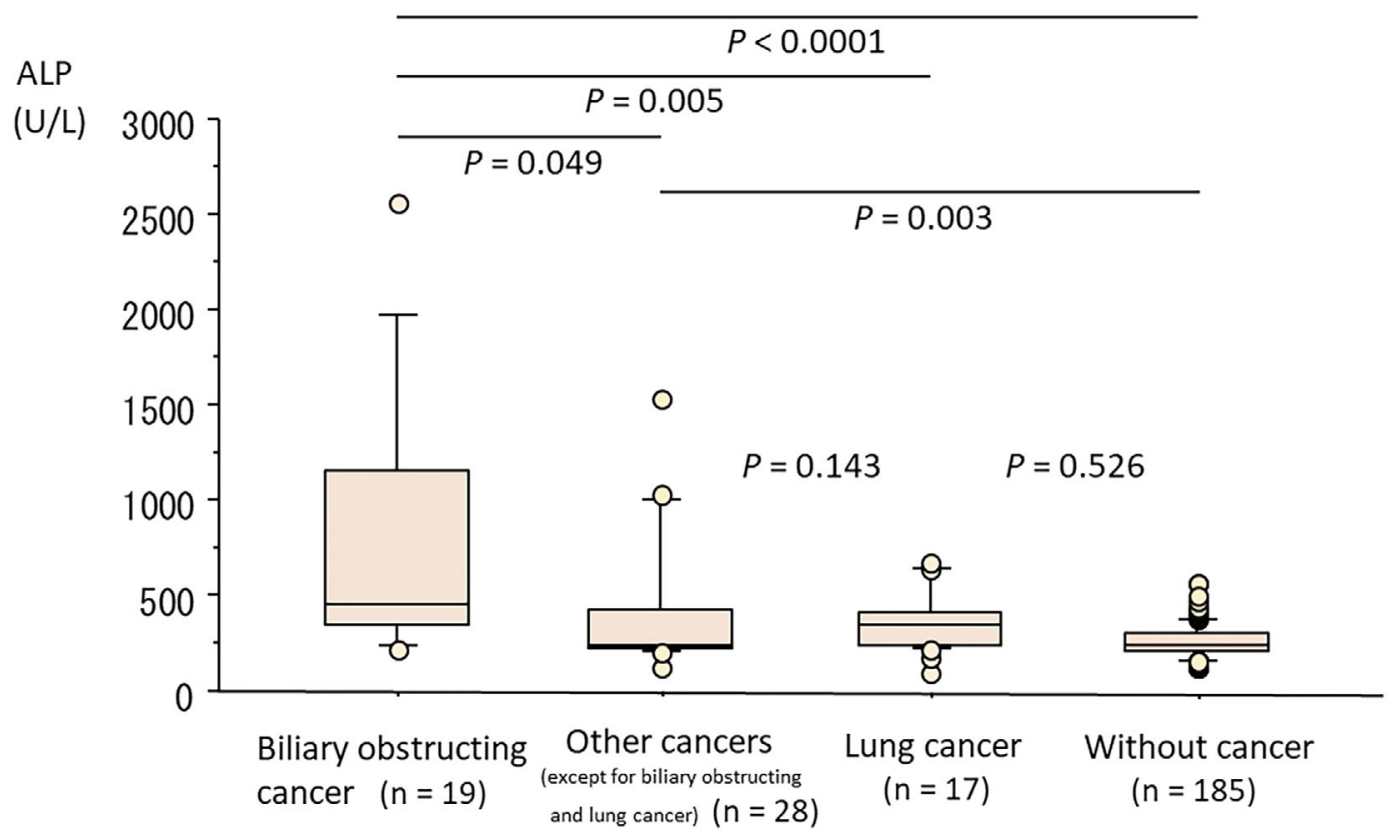

Figure 2. Serum alkaline phosphatase levels in patients with cryptogenic stroke with and without cancer (primary cancer).

variety of clinical disorders (22). Alkaline phosphatase, one of the enzymes that hydrolyze phosphate compounds in alkaline $\mathrm{pH}$ environments, is present in all tissues throughout the body, especially in the liver, bile duct, bone, placenta, and intestinal mucosa. Increased serum alkaline phosphatase levels have been found in patients with cancer with liver and bone metastasis (18), as well as in those with liver diseases, biliary obstruction, and pregnancy and among children $(23,24)$. Regarding the involvement of alkaline phosphatase in cryptogenic stroke, the effects of alkaline phosphatase on blood vessel calcification and arteriosclerosis have been reported (25), as has the association between high serum alkaline phosphatase levels and poor functional outcomes in patients with ischemic stroke, due to the previously considered mechanisms of inflammation, malnutrition, and infection that can occur in active cancer, which has been reported to be associated with elevated alkaline phosphatase levels $(26,27)$. In addition, a study on patients with coronavirus infection reported that deep-vein thrombosis and alkaline phosphatase levels were related (28) and might be involved in thrombus formation, which can also occur in active cancer. These reports suggest that elevated alkaline phosphatase levels might be involved in cryptogenic stroke through mechanisms such as inflammation, malnutrition, in- 


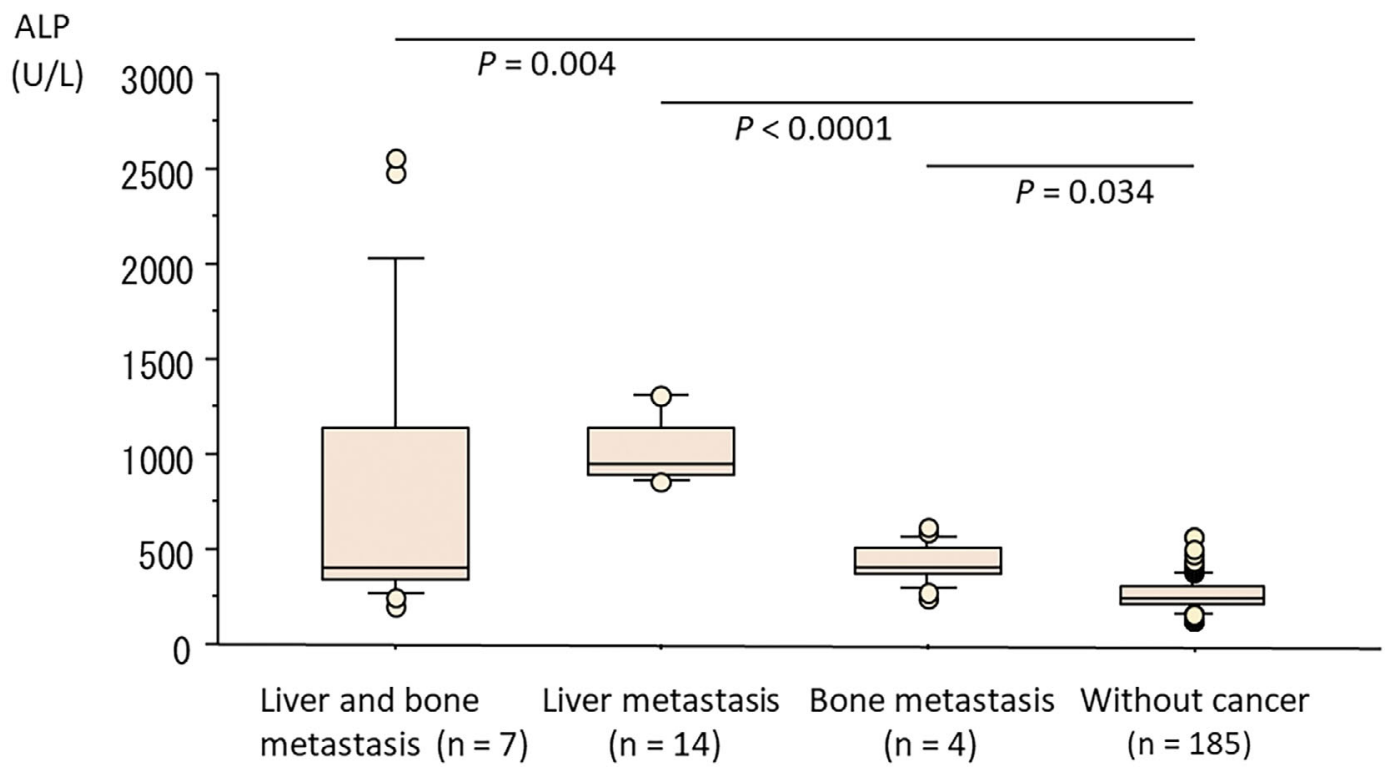

Figure 3. Serum alkaline phosphatase levels in patients with cryptogenic stroke with and without cancer (metastatic cancer).

fection, and thrombus formation that can occur in active cancer, in addition to being the result of cancers that can increase serum alkaline phosphatase levels, such as primary cancer obstructing the liver and biliary systems as well as liver and bone metastasis.

With regard to primary cancer, patients with primary biliary obstructing cancer as well as other primary cancers, excluding biliary obstructing and lung cancer, had significantly higher serum alkaline phosphatase levels than those without cancer, while the serum alkaline phosphatase levels among patients with lung cancer tended to be high, although not significantly so. High serum alkaline phosphatase levels among patients with cryptogenic stroke associated with biliary obstructing cancer may be caused by liver and biliary system obstruction by the primary cancer. Furthermore, serum alkaline phosphatase levels may be assumed to be high in patients with lung cancer due to bone and liver metastases, which can often cause lung cancer. However, our results showed that patients with cryptogenic stroke with lung cancer did not have significantly higher serum alkaline phosphatase levels than those without cancer. Several studies have shown that among the tissue types in lung cancer, small-cell carcinoma had a higher incidence of liver metastasis from lung cancer than squamous cell carcinoma and adenocarcinoma, both of which tend to cause cancerassociated stroke (29). Furthermore, bone metastases of lung cancer often exhibit osteolytic metastases that are less strongly associated with elevated serum alkaline phosphatase (30). Unfortunately, the current study was unable to sufficiently evaluate the primary cancers that tended to cause osteoblastic metastasis associated with elevated serum alkaline phosphatase (31), such as prostate cancer (32), given our small sample size. The high serum alkaline phosphatase levels in patients with other primary cancer, excluding biliary obstructing and lung cancer, may be determined by measuring the alkaline phosphatase isozyme, which would be useful for assessing the origin of alkaline phosphatase within the body.

With regard to metastatic cancer, patients with liver or bone metastasis had significantly higher serum alkaline phosphatase levels than the patients suffering from cryptogenic stroke without active cancer. Liver metastasis can cause elevated serum alkaline phosphatase levels, including alkaline phosphatase isozyme 1 (33-35). White et al. showed that among 39 patients with liver metastasis diagnosed by liver scintigraphy, only 2 with breast cancer had normal serum alkaline phosphatase levels (18). Serum alkaline phosphatase levels may also be elevated in osteoblastic metastases $(31,32)$, mainly due to the increase in alkaline phosphatase isozyme 3 levels $(33,34)$. Furthermore, Nakashima et al. reported that disseminated carcinomatosis of the bone marrow in patients with ischemic stroke with gastric cancer increased the serum alkaline phosphatase levels (36). However, even patients with bone metastasis can have normal serum alkaline phosphatase levels $(23,37)$. Given the presence of some overlap between liver and bone metastasis and our limited sample size, the individual serum alkaline phosphatase levels for liver and bone metastasis could not be sufficiently evaluated.

Together with previous reports, our results suggest that the elevated serum alkaline phosphatase levels in patients with cryptogenic stroke may be attributed to the manifestation of the original nature of alkaline phosphatase, inflammation, malnutrition, infection, and thrombus formation that can occur in active cancer, as well as hepatobiliary system cancer and metastasis into the liver and bone. However, even when the serum alkaline phosphatase levels are normal, the tissue alkaline phosphatase isozymes may be elevated. Therefore, measurement of alkaline phosphatase isozyme values thought to be elevated in certain cancers (33) may be 
useful for further analyzing the origin of elevated serum alkaline phosphatase levels in patients with cryptogenic stroke with active cancer.

Several limitations associated with the present study warrant mention. First, our study measured serum alkaline phosphatase levels using the JSCC method (38), a standard method in Japan, rather than the International Federation of Clinical Chemistry (IFCC) method, which is the international standard (39). The conversion factor is 0.35 when converting from JSCC to IFCC measurement values, although obtaining a conversion coefficient that matches the actual measurement value is difficult given that the slope of the regression equation and the degree of deviation differ depending on the ratio of $\mathrm{B}$ and $\mathrm{O}$ type specimens (40). The alkaline phosphatase measurement method in Japan has been changed from the JSCC method to the IFCC method since April 2020. Second, alkaline phosphatase isozymes, which would be useful for assessing the effect of higher alkaline phosphatase on liver or bone metabolism as well as other primary cancer, could not be investigated. Third, given the small sample size, the features of serum alkaline phosphatase levels in each cancer patients could not be fully investigated. Fourth, cancer metastasis was diagnosed clinically rather than pathologically. Fifth, given that this study was limited to cases of cryptogenic stroke, a study including all patients with cancer is needed to determine whether or not elevated alkaline phosphatase levels also affect the etiology of cryptogenic stroke with active cancer. Sixth, given that our patients with cryptogenic stroke were not sufficiently screened for cancer, there might have been some patients with active cancer within the no-active-cancer group. However, cancer screening was performed at the doctor's discretion based on the symptoms and background of the cryptogenic stroke, and new cancers were found in five patients after stroke.

In summary, high serum alkaline phosphatase levels may be associated with active cancer in cryptogenic stroke. We believe that primary biliary obstructing cancer as well as liver or bone metastasis may be related to the increased serum alkaline phosphatase levels among patients with cryptogenic stroke. In addition to high D-dimer levels and the absence of risk factors for stroke, such as hypertension and a history of ischemic stroke, cancer screening might be considered in cryptogenic stroke when high serum alkaline phosphatase levels are observed. Further studies on alkaline phosphatase isozymes in ischemic stroke associated with cancer may provide more clinically relevant information and monitoring of disease condition.

This study was approved by the Ethics Committee of Nara Medical University School of Medicine. The need for informed consent waived since our study design carried minimal risk.

The authors state that they have no Conflict of Interest (COI).

\section{References}

1. Lee EJ, Nah HW, Kwon JY, Kang DW, Kwon SU, Kim JS. Ischemic stroke in patients with cancer: is it different from usual strokes? Int J Stroke 9: 406-412, 2014.

2. Kim SG, Hong JM, Kim HY, et al. Ischemic stroke in cancer patients with and without conventional mechanisms: a multicenter study in Korea. Stroke 41: 798-801, 2010.

3. Gon Y, Okazaki S, Terasaki Y, et al. Characteristics of cryptogenic stroke in cancer patients. Ann Clin Transl Neurol 11: 280-287, 2016.

4. Cocho D, Gendre J, Boltes A, et al. Predictors of occult cancer in acute ischemic stroke patients. J Stroke Cerebrovasc Dis 24: 13241328, 2015.

5. Karlińska AG, Gromadzka G, Karliński MA, Członkowska A. The activity of malignancy may determine stroke pattern in cancer patients. J Stroke Cerebrovasc Dis 24: 778-783, 2015.

6. Qin QX, Cheng XM, Lu LZ, et al. Biomarkers and potential pathogenesis of colorectal cancer-related ischemic stroke. World $\mathrm{J}$ Gastroenterol 24: 4950-4958, 2018.

7. Kassubek R, Bullinger L, Kassubek J, et al. Identifying ischemic stroke associated with cancer: a multiple model derived from a case-control analysis. J Neurol 264: 781-791, 2017.

8. Cacho-Díaz B, Spínola-Maroño H, Mendoza-Olivas LG, Candelaria M. Platelet count is associated with outcome in cancer patients with stroke. J Neurooncol 140: 569-574, 2018.

9. Grazioli S, Paciaroni M, Agnelli G, et al. Cancer-associated ischemic stroke: a retrospective multicentre cohort study. Thromb Res 165: 33-37, 2018.

10. Izumi T, Nanaura H, Iguchi N, Ozaki M, Sugie K. Low serum eicosapentaenoic acid levels in cryptogenic stroke with active cancer. J Stroke Cerebrovasc Dis 29: 104892, 2020.

11. Graus F, Rogers LR, Posner JB. Cerebrovascular complications in patients with cancer. Medicine (Baltimore) 64: 16-35, 1985.

12. Saynak M, Cosar-Alas R, Yurut-Caloglu V, Caloglu M, Kocak Z, Uzal C. Chemotherapy and cerebrovascular disease. J BUON 13: 31-36, 2008.

13. Stewart FA, Hoving S, Russell NS. Vascular damage as an underlying mechanism of cardiac and cerebral toxicity in irradiated cancer patients. Radiat Res 174: 865-869, 2010.

14. Dardiotis E, Aloizou AM, Markoula S, et al. Cancer-associated stroke: pathophysiology, detection and management (Review). Int J Oncol 54: 779-796, 2019.

15. Schwarzbach CJ, Schaefer A, Ebert A, et al. Stroke and cancer: the importance of cancer-associated hypercoagulation as a possible stroke etiology. Stroke 43: 3029-3034, 2012.

16. Fearon K, Strasser F, Anker SD, et al. Definition and classification of cancer cachexia: an international consensus. Lancet Oncol 12: 489-495, 2011.

17. Hess KR, Varadhachary GR, Taylor SH, et al. Metastatic patterns in adenocarcinoma. Cancer 106: 1624-1633, 2006.

18. White DR, Maloney JJ 3rd, Muss HB, et al. Serum alkaline phosphatase determination. Value in the staging of advanced breast cancer. JAMA 242: 1147-1149, 1979.

19. Lee AY, Levine MN, Baker RI, et al. Low-molecular-weight heparin versus a coumarin for the prevention of recurrent venous thromboembolism in patients with cancer. N Engl J Med 349: 146-153, 2003.

20. Kanda Y. Investigation of the freely available easy-to-use software 'EZR' for medical statistics. Bone Marrow Transplant 48: 452458, 2013.

21. Navi BB, Singer S, Merkler AE, et al. Cryptogenic subtype predicts reduced survival among cancer patients with ischemic stroke. Stroke 45: 2292-2297, 2014.

22. Kaplan MM. Alkaline phosphatase. N Engl J Med 286: 200-202, 1972. 
23. Price CP, Sammons HG. An interpretation of the serum alkaline phosphatase isoenzyme patterns in patients with obstructive liver disease. J Clin Pathol 29: 976-980, 1976.

24. Brichacek AL, Brown CM. Alkaline phosphatase: a potential biomarker for stroke and implications for treatment. Metab Brain Dis 34: 3-19, 2019.

25. Wannamethee SG, Sattar N, Papcosta O, Lennon L, Whincup PH. Alkaline phosphatase, serum phosphate, and incident cardiovascular disease and total mortality in older men. Arterioscler Thromb Vasc Biol 33: 1070-1076, 2013.

26. Ryu WS, Lee SH, Kim CK, Kim BJ, Yoon BW. Increased serum alkaline phosphatase as a predictor of long-term mortality after stroke. Neurology 30: 1995-2002, 2010.

27. Kim J, Song TJ, Song D, et al. Serum alkaline phosphatase and phosphate in cerebral atherosclerosis and functional outcomes after cerebral infarction. Stroke 44: 3547-3549, 2013.

28. Motaganahalli RL, Kapoor R, Timsina LR, et al. Clinical and laboratory characteristics of patients with novel coronavirus disease-2019 infection and deep venous thrombosis. J Vasc Surg Venous Lymphat Disord 9: 605-614, 2021.

29. Görg C, Schwerk WB, Wolf M, Havemann K. Prognostic value of response to chemotherapy using ultrasound in lung cancer with metastatic liver involvement. Bildgebung 57: 70-73, 1990.

30. Otsuka S, Hanibuchi M, Ikuta K, et al. A bone metastasis model with osteolytic and osteoblastic properties of human lung cancer ACC-LC-319/bone2 in natural killer cell-depleted severe combined immunodeficient mice. Oncol Res 17: 581-591, 2009.

31. Coleman RE. Monitoring of bone metastases. Eur J Cancer 34: 252-259, 1998.

32. Killian CS, Vargas FP, Pontes EJ, et al. The use of serum isoenzymes of alkaline and acid phosphatase as possible quantitative markers of tumor load in prostate cancer. Prostate 2: 187-206, 1981.

33. Fishman WH. Perspectives on alkaline phosphatase isoenzymes. Am J Med 56: 617-650, 1974.

34. Moss DW. Alkaline phosphatase isoenzymes. Clin Chem 28:
2007-2016, 1982.

35. Viot M, Thyss A, Viot G, et al. Comparative study of gamma glutamyl transferase, alkaline phosphatase and its alpha 1 isoenzyme as biological indicators of liver metastases. Clin Chim Acta 115: 349-358, 1981

36. Nakashima D, Tanaka E, Yamada $T$, Kojima $Y$, Kitaoji $T$, Nagakane Y. [Recurrent cerebral embolism due to the disseminated carcinomatosis of bone marrow with early gastric cancer]. Rinsho Shinkeigaku (Clin Neurol) 60: 272-277, 2020 (in Japanese).

37. Choi CW, Lee DS, Chung JK, et al. Evaluation of bone metastases by Tc-99m MDP imaging in patients with stomach cancer. Clin Nucl Med 20: 310-314, 1995.

38. Hata A, Fujitani N, Tanaka C, et al. Regression formula to predict the International Federation of Clinical Chemistry and Laboratory Medicine measure of alkaline phosphatase activity in canine blood based on the Japan Society of Clinical Chemistry reference method. J Vet Med Sci 82: 1523-1528, 2020.

39. Schumann G, Klauke R, Canalias F, et al. IFCC primary reference procedures for the measurement of catalytic activity concentrations of enzymes at $37^{\circ} \mathrm{C}$. Part 9: reference procedure for the measurement of catalytic concentration of alkaline phosphatase International Federation of Clinical Chemistry and Laboratory Medicine (IFCC) Scientific Division, Committee on Reference Systems of Enzymes (C-RSE) (1). Clin Chem Lab Med 49: 1439-1446, 2011.

40. Matsushita M, Harajiri S, Tabata S, Yukimasa N, Muramoto Y, Komoda T. [Alkaline phosphatase activity in blood group B or O secretors is fluctuated by the dinner intake of previous night]. Rinsho Byori (Off J Jpn Soc Lab Med) 61: 307-312, 2013 (in Japanese).

The Internal Medicine is an Open Access journal distributed under the Creative Commons Attribution-NonCommercial-NoDerivatives 4.0 International License. To view the details of this license, please visit (https://creativecommons.org/licenses/ by-nc-nd/4.0/).

(C) 2022 The Japanese Society of Internal Medicine Intern Med 61: 639-646, 2022 